\title{
The Development of the Economy and Population Space-Coordinated Analysis of Comprehensive Evaluation:Taking Bijie City as an Example
}

\author{
HONG, Yeying ${ }^{1,2}$ \\ ${ }^{1}$ School of Ethnology and Sociology \\ Gui zhou Minzu University \\ Guiyang City in Guizhou, China \\ ${ }^{2}$ The Communist Party of China Chongqing \\ Fuling District Party Committee Party School Fuling District in Chongqing, China \\ hyeying123@163.com
}

\begin{abstract}
The aim of this study was that discusses the regional difference of regional Population and Economic development level. On the basis of principal component analytical control mechanism of the coordinated development of canonical correlation method. In this paper, we through the construction of Population and Economy coordinated development evaluation index system, and to Comprehensive evaluation and analysis of Bijie region 9 counties ( city) the Population and Economic development level , and to Quantitative analysis of the coordinated development of regional Population and Economy Regional Differences. The results show that: (1) Weining county and Hezhang county and its coordinated development coefficient is in 0.5 the following, at the verge of maladjusted condition, Population and Economic development is contradictory and outstanding, restricted the sustainable development of the region; Zhijin County coordinated development coefficient on $(0.625,0.75]$ interval, belonging to the primary coordination area; Qianxi, Nayong, Jinsha, Dafang, The management committee and Qixingguan district that coordinated development coefficient on ( $0.75,0.875]$ interval, and which belongs to the intermediate coordination area, the Population and Economy system adaptability is not very strong, there are still some instability; (2) The regional Population development and Economic development is not equal to the coordinated development of Population and Economy, even if the two is not necessarily able to coordinate development. The innovation of this paper is that on the basis of the perspective of space and the viewpoint of system, and in order to develop the space of population and economy coordinated comprehensive evaluation analysis.
\end{abstract}

Keywords-Population; Economic growth; Coordinated development; Spatial difference; Bijie City

\section{INTRODUCTION}

The Population problem is primary restrict and affect the economic and social sustainable development and key factors. Since the new century, the Population in the sustainable development of regional Economy plays a more and more important role. The report of the 17th national congress put forward: "to further implement the scientific concept of

Project: This work was sponsored by the Guizhou Minzu University of Doctoral Fund Project [2016MDBSSXM02]. development, we must adhere to the" comprehensive, coordinated and sustainable development, the concept of scientific development is the first point of development, the core is people-oriented, overall consideration as its fundamental approach. Party's eighteen big report on promoting the sustainable development of Population and economic and social coordination, the core concept is the large Population, all construction into the Population, the ultimate goal is to build a harmonious sustainable development of Population, promote the balanced development of the Population. In "much starker choices-and graver consequences-in" development planning, xi jinping pointed out: "emphasis on sustainable development, realize that the coordinated economic development and Population, resources, environment, production development, life wealthy, ecology good civilization development path. "With the social change, and constantly improve the level of economic development and technological strength, at the same time, along with an aging Population, Population structure imbalance and other issues, the coordinated development of Population and Economy development gradually become the sustained and healthy development of regional Economy and even the world faces an important issue.

Bijie City is a typical karst mountain area which on the west and the Population development situation grim, economic development is relatively backward. As of the end of 2015, at the end of Bijie City resident Population of 6.6061 million people, accounting for $18.72 \%$ of the total Population in the province. The natural Population growth rate was $6.09 \%$, higher than that of Guizhou province in $5.80 \%$ $0.29 \%$, significantly higher than the national average of 4.96 per thousand. Very fragile ecological environment, the water loss and soil erosion in the area of $158.14 \times 10^{2} \mathrm{~km}^{2}, 58.89 \%$ of the total land area. In 2015, the region's gross national product (GNP) $14.61 \times 10^{2}$ billion Yuan, accounting for $13.91 \%$ of Guizhou province in $105.03 \times 10^{2}$ billion Yuan, Economy is the third;But the per capita GDP is only 22230 Yuan (in the province of Guizhou ranked the first place), is $74.48 \%$ of the GDP per capita 29847 Yuan in Guizhou. And Bijie City Population and economic development level regional 
distribution is incompatible, the regional difference is obvious. Bijie City Population growth at recent years, severe natural growth rate is high, rich in natural resources, ecological fragility, backward economic development, the Population, resources and environment, the Economy is more outstanding. To establish evaluation index system of Bijie City Population and Economy coordinated development, and put forward the corresponding countermeasures and Suggestions, aims to provide a reference for related departments to make scientific decision[1].

\section{POPULATION AND ECONOMIC DEVELOPMENT COORDINATION} ANALYSIS

\section{A. Construction of index system of Population and economic coordination}

1) Index selection. Population and the coordination of the coordinated development of the guiding ideology of the comprehensive evaluation indicators based on the practice Bijie City, on the basis of the coordinated development theory, sustainable development theory, follow the people-oriented idea, promote the coordinated development of Population, resources, environment and economic society as the goal.Research results at home and abroad for reference, on the basis of the index selection scientific, comprehensive, typicality, operability, and regional principle [2] .To construct the Bijie City Population and Economy coordinated development refers to the system.

2)The coordinated development of the construction of index system. This article select record the membership function for evaluation model of Population and Economy coordinated development of comprehensive evaluation, on the basis of the coordinated development index system [3], the primary index system including: Population development index $\left(X_{i}\right)$ and economic development index $\left(Y_{i}\right)$; Index of every class and contain a secondary indicators, The $X_{i}$ including $\left\{X_{1 i}, X_{2 i}, \ldots X_{n i}\right\}$, See Table 1 :

TABLE I. INDEX SYSTEM STRUCTURE OF THE BUILDING

\begin{tabular}{lll}
\hline & \multicolumn{1}{c}{ Index layer } & Seed index layer \\
\hline $\begin{array}{l}\text { The } \\
\begin{array}{l}\text { coordinated } \\
\text { development } \\
\text { coefficient }\end{array}\end{array}$ & $\begin{array}{l}\text { The Population development } \\
\text { indicators } X i\end{array}$ & $\begin{array}{l}\text { Economic } \\
\text { indicators } Y i\end{array}$ \\
\hline
\end{tabular}

According to these principles, in combination with the practical situation of Bijie City Population and Economic development of regional Population and Economy coordinated development index. Are shown in Table 2.

TABLE II. POPULATION AND ECONOMY COORDINATED DEVELOPMENT EVALUATION INDEX SYSTEM

The evaluation index system

The population development indicators $X_{i}$

Index properties

Economic development indicators $Y_{i}$

Index properties

\section{Total population $\left(x_{1}\right) /$ Million Yuan}

The population density $\left(x_{2}\right) /\left(\right.$ population $\left./ \mathrm{km}^{2}\right)$

The natural population growth rate (x3)/(\%o)

Population sex ratio $\left(x_{4}\right) / \%$

The proportion of urban residents will $\left(x_{5}\right) / \%$

The second, third industry from the proportion of the

$$
\text { population }\left(\mathrm{x}_{6}\right) / \%
$$

The number of health technical personnel $\left(x_{7}\right) /$ population

Each number ten thousand middle school students $\left(x_{8}\right) /$ population

School-age children enrollment rate $\left(x_{9}\right) / \%$

Neutral
Neutral
Inverse indicator
Are indicators
Are indicators

Are indicators

Are indicators

Are indicators

Are indicators

$\operatorname{GDP}\left(y_{1}\right) / 100$ million Yuan
Per capita GDP $\left(y_{2}\right) /$ Yuan

Gross value of industrial output $\left(\mathrm{y}_{3}\right) / 100$ million Yuan

The whole society fixed asset investment $\left(y_{4}\right) / 100$ million

$$
\text { Yuan }
$$

The second industry output value of GDP $\left(y_{5}\right) / \%$

The third industry output value of GDP $\left(y_{6}\right) / \%$

Local fiscal revenue $\left(y_{7}\right) /$ Million Yuan

Per capita net income of farmers $\left(y_{8}\right)$

Disposable income of urban residents $\left(y_{9}\right)$ Yuan

Engel's coefficient $\left(y_{10}\right) / \%$
Are indicators

Are indicators

Are indicators

Are indicators

Are indicators

Are indicators

Are indicators

Are indicators

Are indicators Inverse indicator

1) The standardization of data.In order to eliminate the

\section{B. Population and Economy coordinated evaluation methods and models}

Population and Economy coordinated development is refers to the development between Population and Economy. Population and economic development to cooperate with each other, coordinate with each other, promote each other between the optimization of the development process of [4].Computing system coordination development level, need to go through the following. sample dimension and order of magnitude of the difference between the variables, need for standardization of original data matrix, this paper selects the linear $Z$ - Score method, namely:

$$
Z_{i}=\left(x_{i^{-}} \bar{x}\right) / s
$$

$\left(\mathrm{Z}_{\mathrm{i}^{-}}\right.$As a single index evaluation standard; $X_{i}$-For a single parameter of original value; $X$ - For the average value of a set of index statistics; $S$-For the mean square error of a set of indicators). 
2)Principal component analysis [5]. Principal component analysis to base on the idea of dimension reduction, the numerous original has certain correlation index (such as $\mathrm{Pi}$ index), combined into a new set of comprehensive index has nothing to do with each other instead of the original process. In this paper, using principal component analysis in SPSS 11.5 software, the data $X_{i}(\mathbf{i}=\mathbf{1 , 2}, \cdots, \boldsymbol{p})$ to calculate. According to the characteristics of the correlation coefficient matrix $\lambda_{i}(i=1, \cdots, m)$,The feature vectors $\boldsymbol{e}=\left(\boldsymbol{e}_{1}, \boldsymbol{e}_{2}, \ldots \boldsymbol{e}_{m}\right)$. And standardized values, it is concluded that the correlation coefficient matrix of principal component. According to principal component corresponds to the variance contribution rate $\sum_{i=1}^{m} a_{i}=85 \%$.Can determine the components in the system:

$$
F_{i}=\left(\lambda_{1} z_{x 1}+\lambda_{2} z_{x 2}+\ldots \lambda_{1} Z_{x 1}+\lambda_{i} z_{x i}\right)
$$

According to the corresponding eigenvalue of each principal component extracted by principal component the total proportion of the sum of the characteristic value as the weighting principal component comprehensive model:

$$
F_{i}=a_{1} F_{1}+a_{1} F_{1}+\ldots a_{t} F_{t}
$$

3) Regression analysis .In this paper, $\boldsymbol{i}$ and $\boldsymbol{j}$ are represent the Population development level and the level of economic development, Selection of goodness of fit better and smaller error model, The regression equation of the building Population subsystem(i) and economic subsystem(j).thus calculated $\mathbf{U}_{\mathrm{i} / \mathrm{j}}$ (system and coordinated development, the system of the coordinated development level).

4) The calculation of coordination degree. The author thinks that, coordinated development should include "coordination" and "development" two levels. This article selects the principal component analysis (pca) to determine the level of comprehensive development, on the basis of using record the membership function for computing system between the coordination coefficient and the coordinated development coefficient. Formula [6] is as follows:

$$
C(i / j)=\exp \left[-k_{i}\left(u_{i}-u_{i / j}^{\prime}\right)^{2}\right]
$$

$C(i / j)$. The said $i$ system for $j$ system coordination

coefficient; $u_{i}$ The comprehensive evaluation value of the said $i$ system; $u_{i^{\prime} / j} \quad i$ Said system and coordinated development $j, i$ The coordinated development level of the system; $k_{i}=1 / s^{2}, s^{2}$ show For the variance of $u_{i}$.

Use type can calculate the coefficient of coordination between the regional system $i$ and the system $j$, but can't reflect the region at the time of two systems development level. $u_{i}=0.5, u_{j}=0.5$, Coordination coefficient of the system $i$ and the system $j$ is $1 ; u_{i}=0.9, u_{j}=0.9$, System $i$ and the coordination coefficient of the system $j$ is also to 1 . Obviously, though, the coordination of the two coefficients is
1 , but the level of the development of the latter is obviously higher than the former obviously, though, the coordination of the two coefficients is 1 , but the level of the development of the latter is obviously higher than the former. With said [7].

$$
D(i, j)=\left[C(i, j) \times\left(u_{i}\right)^{\partial} \times\left(u_{j}\right)^{\beta}\right]^{\frac{1}{2}}
$$

$\boldsymbol{D}(\mathbf{i}, \mathbf{j})$ Said $t$ time system $i$ and the system $j$ of the coordinated development coefficient; $\boldsymbol{C}(\mathbf{i} \mathbf{j})$ Coefficient of said system $\boldsymbol{i}$ and $\boldsymbol{j}$ comprehensive development; $\boldsymbol{u}_{\boldsymbol{i}}$ - The composite scores of said system $i$, The system of $\boldsymbol{i}$ comprehensive development leve; $\boldsymbol{u}_{j}$-Said the $\boldsymbol{t}$ system of the comprehensive score $\boldsymbol{j}$, Namely, the comprehensive development level of system $\boldsymbol{j} ; \alpha$ and $\beta$ are and said the weight ,and $\alpha+\beta=1$.In this paper, we study the two systems of Population and Economy, and that is as important as, Namely $\alpha=0.5, \beta=0.5$.

\section{BIJIE CITY POPULATION AND ECONOMIC COORDINATED DEVELOPMENT EVALUATION OF EMPIRICAL RESEARCH}

\section{A. Regional overview and data sources}

1) The study area basic situation. Bijie City lies in the Northwest of Guizhou province, East longitude 103 36'$106^{\circ} 43^{\prime}$ and latitude26 $21^{\prime}-27^{\circ} 46^{\prime}$ Land area is $2.69 \times 10^{7}$ $\mathrm{hm}^{2}$. Is that located in the eastern Yunnan-Guizhou plateau to the low mountain hilly excessive slope zone, belong to two big river, the Yangtze river and the Zhujiang river area accounts for $95.38 \%$ of the Changjiang river valley, the pearl river basin area accounted for $4.62 \%$, is a typical karst mountain area in the province of Guizhou [8].

2) Source of data and instructions. This article selects 2015 Bijie City Population and economic development level as the cross section data, using SPSS analysis software for processing, 11.52 in 7 counties of Bijie City Population and economic development to make comprehensive evaluation. Data from the Bijie past 60 years (1949-2009), and 2016 statistical bulletin Bijie City economic and social development.

\section{B. Population and economic comprehensive development level}

Population and Economic development level according to the weighted average method, integrated system using formula (1) to standardize data processing, according to the formula (3),(2) and formula to calculate the comprehensive development level of Population system and economic system, As shown in Table 3: 
TABLE III. BIJIE CITY IN 2015 COUNTIES (AREA) OF POPULATION AND ECONOMIC DEVELOPMENT LEVEL OF INTEGRATED SYSTEM

\begin{tabular}{cccccccccc}
\hline City & Qi Xinguan & Bai Guanwei & Da Fang Qian Xi & Jin Sha & Zhi Jin & Na Yong & Wei ning & He Zhang \\
\hline $\begin{array}{c}\text { The population comprehensive development } \\
\text { level }\end{array}$ & 2.195 & 0.927 & -0.316 & 0.979 & 0.071 & -0.439 & -0.402 & -1.157 & -0.729 \\
$\begin{array}{c}\text { Comprehensive economic development level } \\
\text { n }\end{array}$ & 2.348 & 1.024 & -0.848 & 1.325 & 3.149 & -1.350 & 0.700 & -2.683 & -2.640 \\
\hline
\end{tabular}

\section{The coordinated development coefficient calculation}

From Table 3, the disparity between Population and economic comprehensive development index of Bijie City, weining and hezhang county Population and economic comprehensive development level of the word. To reduce the error caused by a huge gap, the coordination degree is based on the thought of efficacy coefficient, the modification of the data in Table 3, after transforming the coordination coefficient in $[0.6,1]$ interval, Formula for:

$$
v_{i j}=\left\{\left[u_{i j}-\min \left(u_{i j}\right)\right] /\left[\max \left(u_{i j}\right)-\min \left(u_{i j}\right)\right]\right\} \times 0.4+0.6
$$

Using the formula (4), (5) and formula (6), according to a 2015 Bijie City Population and economic development level as the cross section data, calculate the Bijie City 1 and 7 county city Population coordination coefficient of the system and economic system and the coordinated development coefficient. The result is show that in Fig. 1.

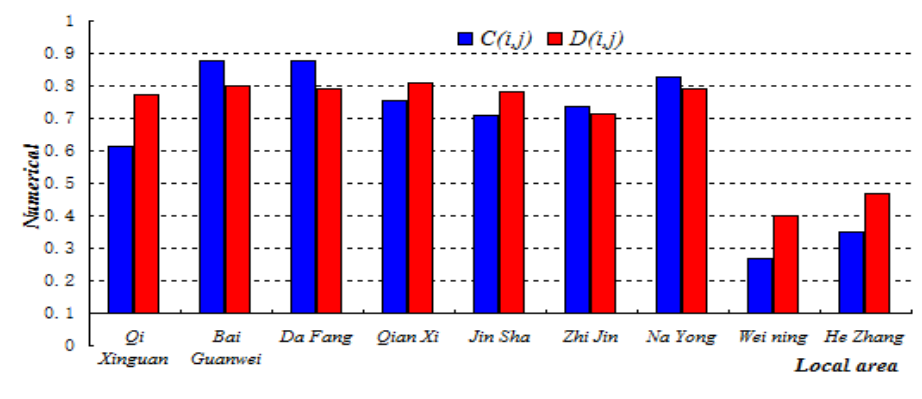

Fig. 1. 2015 Bijie City countiesof Population and Economy system coordination coefficient and coordinated development coefficient

According to the size of the coordinated development coefficient $\mathrm{D}$ value, which can be divided into the type of Population and Economy coordinated development, the greater the $\mathrm{D}$ value, and show that the higher the degree of coordinated development between the regional system. With uniform distribution function method, this paper will coordinate degree is divided into eight types, See Table 4.

TABLE IV. COORDINATION DIVISION STANDARD

\begin{tabular}{|c|c|c|c|c|}
\hline Coordination type & Serious imbalance & Moderate disorders & Mild disorder & On the verge of disorder \\
\hline Coordination degree (D) & $(0,0.125]$ & $(0.125,0.25]$ & $(0.25,0.375]$ & $(0.375,0.5]$ \\
\hline Coordinated type & Barely coordination & Primary coordination & Intermediate coordinate & Good coordination \\
\hline Coordination degree (D) & $(0.5,0.625]$ & $(0.625,0.75]$ & $(0.75,0.875]$ & $(0.875,1]$ \\
\hline
\end{tabular}

According to Table 4 division standards, Weining and Hezhang coordinated development coefficient under 0.5, belong to the endangered dislocation area, the main reason is the comprehensive development level of the two regions Population and economic comprehensive development level is negative, the gap between the two systems is larger at the same time, makes the Population and economic development not harmonious; Coordinated development coefficient in zhijin county $(\mathbf{0 . 6 2 5}, \mathbf{0 . 7 5}$ ] interval, belongs to primary coordinated area, the main reason is that although the negative Population and economic comprehensive development level, but the gap is smaller, the two systems and presents the primary coordinate area; QianXi, JinSha, Nayong, DaFang, and the coordinated development coefficient on the management committee and Qi Xingguan (0.75, 0.875] interval, belong to the intermediate coordinate area, the reason is that Population of five regional comprehensive development level and the comprehensive economic development level is close to, better coordination, at the same time, the overall strength strong Population and economic development.

\section{CONCLUSION}

Based on the karst mountain area in Bijie City which is as the research object, from the perspective of space is analyzed using Bijie City seven counties the differences between the two areas, so as to explore an area with other regional coordinated development between the gap and existing problems. According to the study the following conclusions:

1)Bijie City are analyzed through space view. Seven counties 2 area of Population and Economy coordinated development level of the huge differences between weining map and hezhang county in 0.5 the following, the coordinated development coefficient shows it is in disorder, the contradiction between Population and economic development, restricted the regional sustainable development. Coordinated development coefficient in zhijin county (0.625, 0.75] interval, belongs to primary coordinated area; QianXi, sands, harmony, generous, and the coordinated development coefficient on the management committee and the seven towns $(\mathbf{0 . 7 5}, \mathbf{0 . 8 7 5}]$ interval, belong to the intermediate coordinate area, the fitness of Population and economic system are not very strong, there are still some instability. Therefore, implement the strategy of 
balanced development of the Population and improve the Population quality, promote the Population reasonable distribution.

2)Development of regional Population or Economic development is not equal .To the coordinated development of Population and Economy, even if the two direction does not necessarily can harmonious development. According to economic theory, Zhijin, Weining, Nayong three counties such as per capita GDP level of development and its coordination degree consistent seating arrangement; Jinsha higher per capita GDP (ranked first), The coordination degree of seating arrangement is not high (fourth); Qianxi per capita GDP is not high (fourth), the coordination degree of seating arrangement is higher (ranked first). Multi-scale spatial area development and diversified, and its coordination is more complicated. Such as the coordination degree of the highest qianxi, by the end of 2015, the poverty rate is as high as $11.60 \%$. Therefore, the transformation of the mode of Economic development, optimize the Economic layout, promote the overall development of the regional Economic level.

\section{ACKNOWLEDGMENT}

This work was sponsored by the Guizhou Minzu University of Doctoral Fund Project [2016MDBSSXM02].

\section{AUTHOR IN BRIEF}

HONG, YeYING, male, People in Shucheng City of Anhui Province , China;Doctoral student of Gui zhou Minzu University, lecturer, Chongqing Fuling District Committee
Party School of CPC; Mainly engaged in Economics of Population and Social policy research direction in ethnic minority areas,E-mail:hyeying123@163.com

\section{REFERENCES}

[1] HONG,Yeying.Study on the Relationship between Population Urbanization and Economic Growth,Industrial Structure:Taking Bijie City as an Example [A]. Prof.Xiaonan Xiao.Proceedings of the 1st International Seminar on Education, Innovation and Economic Management (SEIEM 2016) [C]. Atlantis Press, 2016(75).pp.126-129.

[2] LIN FanYuan,DONG Junli. The Study on the Regional Evaluating and Suggestion of Shandong 's Population and Economy Coordinated Development[J]. Northwest Population Journal,2010(2),pp. 74-79. (In Chinese).

[3] Wang Hongfen. Introduction to measurement geography[M].Ji Nan: Shandong education press, 2001,pp.50-60. (In Chinese).

[4] II Jingnen. New Population theory [M].Bei Jin: The Population of China press, 2003, pp.265-267. (In Chinese).

[5] Gao Xiangbao, Dong Hanqing. Data analysis and the application of SPSS[M].Bei Jin: Tsinghua university press ,2007.pp.341-343. (In Chinese).

[6] Wang Guowei. The establishment of the theory of the national Economy coordination coefficient of the system [J].Statistical Research, 1995(4),pp.21-22. (In Chinese).

[7] Liu Xiaolin. Regional coordinated development of Population, resources, environment and economic system of quantitative evaluation[J].Statistics and decision, 2007(1),pp.25-27. (In Chinese).

[8] Wang Jinying, Li Jingbo. Re-checking the Relationship between Population and Economic Growth: Based on Population's Active Factors and Economic model [J]. Chinese Journal of Population Science,2016(3),pp.12-24. (In Chinese) 